\title{
LA RELIGIOSIDAD DE LAS COFRADÍAS EN LA SEVILLA DE LOS SIGLOS XIV AL XVI: SACRAMENTOS, CICLO LITÚRGICO Y PRÁCTICAS DEVOCIONALES ${ }^{1}$
}

\author{
CONFRATERNITIES AND THEIR RELIGIOUSNESS IN SEVILLE \\ DURING $14^{\mathrm{TH}}$ TO $16^{\mathrm{TH}}$ CENTURIES: SACRAMENTS, LITURGICAL \\ YEAR AND DEVOTIONAL PRACTICES
}

\author{
Juan Carlos Arboleda Goldaracena \\ Universidad Pablo de Olavide de Sevilla \\ jcarbgol@upo.es
}

RESUMEN: En este trabajo queremos presentar la amplia variedad de prácticas de piedad y devoción llevadas a cabo por los miembros de las cofradías en la Sevilla de finales de la Edad Media y comienzos de la modernidad. Lo haremos mediante el uso de una fuente fundamental para estudiarlas y para conocer este tipo de fenómenos: las reglas de estas instituciones. Por su propia naturaleza, los documentos procedentes de estas asociaciones, formadas preferentemente por laicos, reflejan plenamente cómo vivían y sentían los miembros de este gran colectivo dentro de la Iglesia católica. Por tanto, estudiar la religiosidad cofrade es también estudiar el sentir religioso de los laicos. Nos centraremos en tres aspectos fundamentales: los sacramentos, el año litúrgico y el conjunto de otras prácticas de piedad a las que los creyentes recurrían para manifestar su devoción a Dios, la Virgen María y los santos.

PAlABRAS ClaVE: religiosidad; cofradías; sacramentos; año litúrgico; devociones.

ABSTRACT: In this paper we aim to show the different kinds of devotions which confraternities practiced in Seville at the end of the Middle Ages and the beginning of the Early Modern period. In order to achieve our purpose we have used confraternities' rules. These associations were generally composed of laypersons, which means that their documents show how this people felt and lived. We have studied three different aspects: sacraments, the liturgical year and the different types of religious practices and devotions used by people in order to express their devotion to God, the Virgin and the saints.

KEYWORDS: religiousness; confraternities; sacraments; liturgical year; devotions.

1. Abreviaturas utilizadas: $\mathrm{BGUS}=$ Biblioteca General de la Universidad de Sevilla; $\mathrm{AHN}=\mathrm{Ar}-$ chivo Histórico Nacional; AHPS = Archivo Histórico Provincial de Sevilla; BN = Biblioteca Nacional. 


\section{INTRODUCCIÓN}

La religiosidad cristiana ${ }^{2}$, esto es, el extenso panorama de prácticas y devociones mediante las cuales los creyentes manifiestan su participación de las verdades proclamadas por la Iglesia (en nuestro caso, la católica) puede estudiarse a través de muchas y muy diversas fuentes y maneras en función de los diferentes marcos espacio-temporales en que nos movamos. Pretendemos acercarnos en este trabajo a la definición de ese panorama en la Sevilla de finales de la Edad Media y comienzos de la modernidad centrándonos especialmente en las cofradías, y por ende en los laicos, que han sido tradicionalmente los grandes olvidados en los estudios sobre Historia de la Iglesia en general y sobre religiosidad en particular. Para la misma ciudad y período contamos con un estudio que reflejó la religiosidad de los sevillanos ${ }^{3}$ utilizando una fuente documental de gran valía, los protocolos notariales, y abarcando un arco temporal desde 1441 a $1504^{4}$. Nosotros proponemos la utilización de otra fuente, como son las reglas de las propias hermandades y cofradías, algo que hasta el momento no se había realizado para ilustrar un panorama que presenta multitud de matices diversos en función de la óptica desde la que se estudie.

Definimos las hermandades y cofradías ${ }^{5}$ como asociaciones preferentemente de laicos, hombres y mujeres, que se unen para diversos fines (principalmente, adorar a Dios y venerar a la Virgen y a los santos; hacer penitencia; y ejercer la caridad), siempre teniendo como marco el de una vida cristiana según las enseñanzas evangélicas ${ }^{6}$. Nacen en la Plena Edad Media y van configurándose en torno a diversas tipologías, entre las cuales destacarán por su importancia las cofradías de Semana Santa o Pasión, que no surgirán sino hasta finales del siglo XV y, sobre todo, durante las primeras décadas del XVI. Nosotros, en principio, no haremos distinción en cuanto a la diversidad de cofradías, ya que todas y cada una de estas corporaciones, sin importar los motivos de su fundación, sus fines secundarios o

2. Para un estudio más profundo del concepto, pueden verse las siguientes referencias: Maldonado 1989; Mandianes 1989.

3. Para conocer los entresijos de la religiosidad cristiana durante los siglos estudiados, o con especial atención al caso de Sevilla, pueden consultare, entre otras, estas referencias: Fernández Conde 2011, pp. 376-416; Sánchez Herrero 1989, 2004. No es objeto de este trabajo definir el amplio panorama devocional en la Sevilla de la época, pues ya lo han hecho otros, si bien podemos destacar algunos rasgos definitorios básicos: una supremacía sacramental centrada en el Bautismo, la Eucaristía y la Penitencia; el seguimiento constante del ciclo litúrgico, con dos puntos fuertes: la Navidad y la Pascua de Resurrección; y la práctica de determinadas devociones cristológicas, marianas y de los santos, destacando la adoración a Jesús Sacramentado y la veneración de determinadas advocaciones marianas y santos locales o ligados a determinadas órdenes religiosas.

4. Pérez González 2005. Este trabajo cuenta con una parte dedicada a la religiosidad en general y otra centrada en las cofradías.

5. Utilizamos ambos términos indistintamente, puesto que en la práctica aluden a las mismas realidades. Para un profundo conocimiento sobre ellas es necesario acudir a las obras del profesor José Sánchez Herrero. Entre las muchas obras que ha escrito, solo o en colaboración con otros autores, destacamos algunas: Sánchez Herrero 1985, 1988, 1995, 1996, 1999, 2003, en línea; Sánchez Herrero, Pérez González 1999.

6. Sánchez Herrero 2003, pp. 21-22. 
los titulares a los que daban culto, ponían en práctica (como no cabría esperarse de otra manera) el modelo de vida cristiano ${ }^{7}$.

Para la investigación nos hemos valido documentalmente, como ya hemos mencionado, de las reglas de estas instituciones, que constituyen el conjunto de normas y cánones que rigen la vida interna y las actividades públicas de estas corporaciones: sus fines y objetivos religiosos, el culto y su residencia, el gobierno y sus oficiales, la gestión y el control del patrimonio, la caridad, la estación de penitencia, etc. Ya desde los comienzos del asociacionismo cofrade, los miembros de las hermandades tuvieron la necesidad de fijar por escrito los distintos estatutos que serían la base de su vida en común. Estas reglas, desde el siglo XVI, habían de ser aprobadas por la preceptiva autoridad eclesiástica, y en la segunda mitad del siglo XVIII se impuso la necesidad de un control adicional por parte de la Cámara de Castilla ${ }^{8}$.

Las reglas empleadas para la elaboración de nuestro trabajo proceden de dos fuentes distintas: por un lado, un corpus ${ }^{9}$ recopilado y publicado hace ya algunos años por los profesores Sánchez Herrero y Pérez González. El corpus en cuestión se compone de un total de 119 reglas de hermandades y cofradías andaluzas de los siglos XIV, XV y XVI, de las cuales 36 pertenecen a la ciudad de Sevilla. No obstante, nosotros hemos trabajado con 34 de ellas ${ }^{10}$, después de excluir dos al

7. No obstante, en algunas partes del presente trabajo, como veremos, sí será pertinente hacer algunas distinciones. En cualquier caso, y para conocer las diversas tipologías de hermandades y cofradías, recomendamos acudir a las obras de referencia indicadas en la nota 5.

8. Sánchez Herrero 2003, p. 22.

9. Sánchez Herrero, Pérez González 2002.

10. I. Hermandad y Hospital de Peregrinos de Nuestra Señora del Pilar, 1336; II. Hermandad del Hospital del Salvador o de la Misericordia, 1349, 1390; III. Hermandad y Cofradía de San Pedro Apóstol y Mártir o de los correeros o guarnicioneros, ha. 1450; IV. Hermandad de la Santa Casa de la Misericordia, 1476, 1518; V. Cofradía y Hermandad de la Santa Vera Cruz, 1538; VI. Hermandad de Nuestra Señora de la Consolación y Doce Apóstoles, 1537, 1545; VII. Hermandad y Cofradía de las Angustias de Nuestra Señora la Virgen Santa María, 1541; VIII. Hermandad y Cofradía del Santísimo Sacramento de la parroquia del Salvador, 1543; IX. Hermandad y Cofradía de la Santísima Trinidad, 1544; X. Hermandad y Cofradía de la Pura y Limpia Concepción de Nuestra Señora la Virgen María del Convento de Regina, 1549; XI. Hermandad, Cofradía y Esclavitud del Santísimo Cristo de la sin Lanzada, de la nave del Lagarto de la Catedral de Sevilla, siglo XVI; XII. Hermandad y Cofradía de los Negritos, 1558; XIII. Hermandad y Cofradía de Nuestra Señora de la Cabeza, 1564; XIV. Hermandad y Cofradía de las Ánimas de San Vicente, 1564; XV. Hermandad y Cofradía de Jesús Nazareno y Santa Cruz de Jerusalén, 1564, 1567, 1578; XVI. Hermandad y Cofradía de la Santa Verónica, 1565; XVII. Hermandad y Cofradía de las Ánimas del Purgatorio de la parroquia del Salvador, 1565, 1567; XVIII. Hermandad y Cofradía de la O, 1566; XIX. Hermandad y Cofradía del Santísimo Sacramento de San Bernardo, 1570; XX. Hermandad y Cofradía del Nombre Santísimo de Jesús, 1572; XXI. Hermandad y Cofradía del Dulce Nombre, 1572, 1574; XXII. Hermandad y Cofradía de Nuestra Señora de la Cabeza, 1573; XXIII. Hermandad y Cofradía de la Santa Expiración de Jesucristo, 1575; XXIV. Hermandad y Cofradía Sacramental de la parroquia de San Martín, 1580; XXV. Hermandad y Cofradía de la Preciosa Sangre, 1581; XXVI. Hermandad y Cofradía de Nuestra Señora de la Granada, 1586; XXVII. Hermandad y Cofradía del Buen Fin, 1593; XXVIII. Hermandad y Cofradía del Señor Santiago Apóstol o de los sombrereros, 1593; XXIX. Hermandad y Cofradía de Nuestra Señora de Cuatrovitas, 1595; XXX. Hermandad y Cofradía de los Sagrados Clavos de Nuestro Redentor Jesucristo, Virgen María de los Remedios y Glorioso San Juan Evangelista, 1595; XXXI. Hermandad y Cofradía de Nuestra Señora de la Esperanza, 1595; XXXII. Hermandad y Cofradía de Nuestra Señora del Buen Viaje, 
comprobar que en realidad la parte del texto correspondiente a los siglos indicados era bastante escasa, siendo ampliadas con posterioridad. Por otro lado, hemos trabajado con diversas reglas recopiladas posteriormente procedentes de diversos archivos y repositorios, algunas de ellas halladas y transcritas por nosotros mismos y otras ya publicadas o en vías de publicación. Indicamos el nombre de la corporación y la procedencia de la regla ${ }^{11}$.

La primera de las reglas data de 1336 y la última se remonta a 1601, por lo que ese es el marco temporal exacto de nuestro trabajo. En cuanto a su distribución por siglos, dos de ellas pertenecen al siglo XIV, otras dos al XV y las restantes al siglo XVI. Se aprecia claramente una supremacía de este último siglo sobre los anteriores, pero esto se debe precisamente al notable auge que experimentó el fenómeno cofrade durante esta centuria. No obstante, creemos que no se produce una ruptura entre uno y otro siglo (XV y XVI) en lo que a religiosidad se refiere, de manera que los modelos de sentir religiosos medievales se mantendrán en pie durante la primera centuria moderna, o al menos hasta la irrupción de las doctrinas impulsadas por el Concilio de Trento y, lo que es más importante, su llegada efectiva a la mayoría del pueblo cristiano ${ }^{12}$. Dado que las reglas están publicadas en formato electrónico, indicamos en las notas a pie de página el número de cada regla (en cifras romanas ${ }^{13}$ ) y el del capítulo o signatura que se le ha asignado en la citada obra (en caracteres arábigos) ${ }^{14}$.

En cuanto al margo geográfico de nuestro estudio, hemos indicado que nos centraremos en la ciudad de Sevilla. Las conclusiones extraídas de la investigación son significativas al tratarse de la capital del reino del mismo nombre, así como de la sede diocesana, que en estos momentos ocupaba las actuales provincias de Sevilla y Huelva, además de una parte importante de la de Cádiz. Estamos por

1596; XXXIII. Hermandad y Cofradía del Santísimo Sacramento de la parroquia de San Julián, 1599; XXXIV. Hermandad y Cofradía de Nuestra Señora de Regla y Potencia de Cristo, 1601.

11. XXXV. Hermandad de Doncellas del Hospital de la Misericordia o Congregación de la Anunciación, 1522. Biblioteca General de la Universidad de Sevilla (BGUS), signatura A 042/362; XXXVI. Cofradía del Traspaso y Soledad de Nuestra Señora, 1555. Publicada en: Cañizares Japón 2014; XXXVII. Cofradía del Santísimo Sacramento de la parroquia de San Lorenzo, 1558. Archivo Histórico Nacional (AHN), legajo $n^{\circ} 1148-17$; XXXVIII. Hermandad de Nuestra Señora de la Estrella y Cofradía de cargadores del puerto de Sevilla, 1566. Archivo Histórico Provincial de Sevilla (AHPS), Protocolos Notariales, Leg. 1080, oficio II, libro II de 1566, ff. 1359r-1364v; XXXIX. Hermandad y Cofradía del Gran Poder y Traspaso de Nuestra Señora, 1570. AHN, sección Códices, 1173B. Publicada en: Mira Caballos 2004; XL. Cofradía del Santísimo Sacramento de la parroquia de Santa Ana, 1572. AHN, sección Consejos, legajo 704, nº 16; XLI. Hermandad del Señor San Pedro Mártir, 1589. Biblioteca Nacional (BN), signatura A-C4; XLII. Hermandad de la Misericordia, 1599. BGUS, signatura A Res. 35/4/03.

12. Un estudio más detallado sobre la realidad del siglo XVI y el influjo de la Contrarreforma en las cofradías andaluzas puede encontrarse en: Arboleda Goldaracena 2010. Para otros ámbitos peninsulares, puede verse el trabajo de Mantecón 1990.

13. A las reglas que no proceden del corpus les hemos asignado números consecutivos para seguir el mismo sistema de citación. Dichos números son los que aparecen en la nota 11.

14. A veces el capítulo no recibe una numeración concreta, sino que se engloba dentro de las diferentes introducciones y preámbulos presentes en las reglas. En tal caso, indicamos "Int". 
tanto ante la capital del sur peninsular, algo que permite extraer conclusiones extrapolables al resto del área de influencia ${ }^{15}$.

Para abordar nuestro estudio de las prácticas devocionales cristianas que manifestaban los miembros de las hermandades y cofradías nos ocuparemos de ellas estudiándolas en tres grupos: los sacramentos, los momentos del año litúrgico y otras manifestaciones de devoción y piedad. Se sobreentiende que todas ellas van dirigidas a manifestar adoración a Dios a través de cada una de las tres personas de la Trinidad y veneración a la Virgen María y los santos, todos ellos principales protagonistas de la fe cristiana ${ }^{16}$.

Los sacramentos son y han sido a lo largo de la historia del cristianismo momentos fundamentales de celebración y vivencia de la presencia de Dios en la Iglesia y en las vidas de los creyentes. Las cofradías no han sido nunca ajenas a la importancia de la celebración sacramental como signo de pertenencia activa a la comunidad eclesiástica, por lo que es obvio que su presencia en la documentación por nosotros estudiada es fundamental para conocer la concepción concreta que tenían los cofrades con respecto a los distintos sacramentos reconocidos por la Iglesia católica.

Por otra parte, el ciclo de la vida de los cristianos se organiza en torno al año litúrgico, para conmemorar de forma periódica los distintos momentos de la vida terrena y la subida a los cielos de Jesús. Los cofrades, siguiendo las directrices marcadas por la Iglesia, organizaban también sus vidas cristianas en torno a este ciclo, por lo que la distribución temporal del año litúrgico se hace patente en las reglas de las corporaciones.

Por último, no podemos pasar por alto todos aquellos momentos en los que, a través de diversas prácticas devocionales y de piedad, los cristianos pertenecientes a las cofradías se dirigían a la divinidad para manifestar su fe, realizar diversas peticiones o dar gracias por los favores recibidos. Estudiamos estas prácticas como cauce privilegiado de relación personal entre Dios, la Virgen y los santos con sus creyentes y devotos.

\section{LOS SACRAMENTOS}

Siete son los sacramentos reconocidos por la Iglesia católica: bautismo, confirmación, penitencia, comunión, matrimonio, orden sagrado y extremaunción ${ }^{17}$. Las

15. Una recopilación de los estudios realizados hasta la fecha en referencia al ámbito castellano puede verse en: Martín-Viveros Tajuelo 2012.

16. El panorama general de la religiosidad cofrade puede completarse con el estudio de otros aspectos, como el ejercicio de la caridad, la asistencia ante la muerte o las devociones particulares. Estos aspectos han sido abordados en otros trabajos, ya publicados o en vías de publicación. Véanse las referencias: Arboleda Goldaracena 2013, 2014, 2015. Un estudio más genérico, enfocado en la asistencia social, es el de: Lozano, Torremocha 2013.

17. Para su significación y práctica en el cristianismo medieval, puede verse: Mitre 2004. Con respecto al siglo XVI y la influencia de la Contrarreforma, puede hallarse un resumen en: García Cárcel, Palau I Orta 2006, p. 209. 
referencias a ellos en las reglas no son muy abundantes, algo que interpretamos no como un desconocimiento de los mismos, sino como una prueba fehaciente de su integración dentro de la vida de los cristianos, que los asumían con naturalidad y, en líneas generales, podemos afirmar que, salvo en algún caso que veremos, los conocían y acudían a ellos, puesto que no encontramos datos que refieran lo contrario. En ocasiones se hace referencia a los sacramentos de la Iglesia en general ${ }^{18}$.

El sacramento del bautismo no se menciona directamente en la documentación, ya que se sobreentiende que para formar parte de una cofradía era condición indispensable ser cristiano, disposición que se recoge explícitamente en las reglas de algunas de ellas ${ }^{19}$. A veces no solamente basta con ser cristiano, sino que el candidato a cofrade ha de ser cristiano viejo y no converso ${ }^{20}$. El Sínodo de Sevilla de $1490^{21}$ definió todos los procedimientos para la administración correcta de este sacramento $^{22}$ : debía realizarse por inmersión, registrarse en los libros que habían de hallarse al efecto en las parroquias y contar con la presencia de entre uno y cuatro padrinos.

La confesión se recomienda como una práctica frecuente que ayuda a encauzar correctamente la vida cristiana y evitar el pecado ${ }^{23}$. Los cofrades no obedientes deben recurrir a ella ${ }^{24}$, al igual que todos sus hermanos antes del cabildo de elección de oficiales, como sucede en algunas cofradías ${ }^{25}$. El Concilio Provincial de Sevilla de 1512 definió este sacramento como la medicina del alma ${ }^{26}$.

Normalmente, la confesión ha de ir unida a la comunión: previamente a las prácticas penitenciales de Semana $\operatorname{Santa}^{27}$, durante la enfermedad ${ }^{28}$ o con ocasión de las fiestas de las cofradías ${ }^{29}$.

La comunión se recomienda igualmente para evitar el pecado ${ }^{30}$ y su práctica era habitual antes de la elección de oficiales ${ }^{31}$, previamente a las procesiones ${ }^{32}$ o el último domingo de cada mes $^{33}$. En ocasiones, las reglas establecen que el hermano mayor de la cofradía ha de exhortar al resto de cofrades para que comulguen con frecuencia ${ }^{34}$, bajo pena si no lo hacen varios años seguidos. La extremaunción ha de administrarse igualmente a los enfermos próximos a morir ${ }^{35}$.

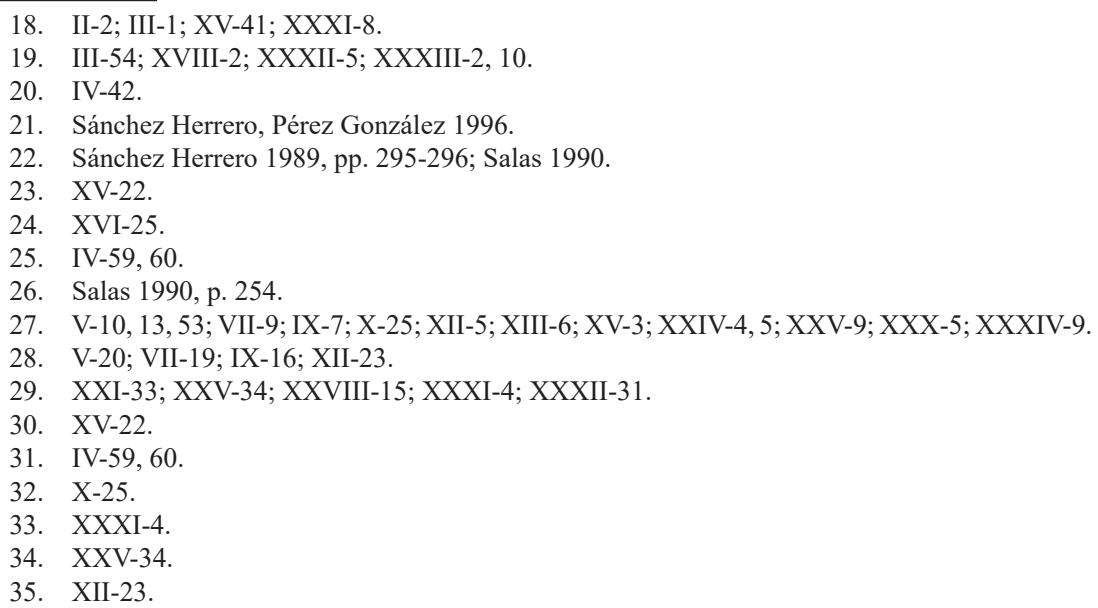


El sacramento del orden sagrado lo documentamos solamente en un caso: una de las cofradías especifica en sus reglas que los cofrades habían de acudir a la primera misa de los clérigos que se ordenasen y fuesen previamente hermanos de la corporación ${ }^{36}$. No obstante, hemos de destacar que la presencia de miembros del clero, sobre todo secular, dentro de las cofradías, ha sido siempre muy activa ${ }^{37}$.

El sacramento del matrimonio ${ }^{38}$ era fundamental para los cofrades, por cuanto abría las puertas de las corporaciones a todo el núcleo familiar ${ }^{39}$ : el cofrade, su mujer y sus hijos, de manera que toda la familia podía disfrutar de los beneficios de pertenencia a la institución, sobre todo en el caso de las honras fúnebres. No obstante, la documentación no es muy exhaustiva en lo que se refiere a la celebración de este sacramento, aunque hemos podido señalar algunos casos en que se hace mención a diversos enlaces matrimoniales: algunas cofradías especifican que si un cofrade contrae matrimonio, los clérigos pertenecientes a la cofradía no están obligados a asistir a la ceremonia ${ }^{40}$. Las reglas recogen también la posibilidad de que la viuda de un cofrade vuelva a casarse ${ }^{41}$, dejando en tal caso de pertenecer a la cofradía. Por último, se menciona una de las actividades socio-caritativas ejercidas por las cofradías: la dotación de doncellas pobres para el matrimonio ${ }^{42}$.

Para cerrar este apartado, constatamos que no hemos documentado ni una sola referencia al sacramento de la confirmación. Su administración no era muy frecuente en la época estudiada, ya que ni en el Sínodo de 1490 ni en el Concilio Provincial de 1512, ambos celebrados en Sevilla, se menciona este sacramento ${ }^{43}$. En el Sínodo de Cádiz de 1591 se afirma que se recibía poco ${ }^{44}$. El primer caso documentado en la parroquia de San Andrés de Sevilla data de $1600^{45}$, por lo que es posible que en el resto de parroquias la situación fuera similar.

\section{El AÑO LITÚRGICO}

El año cristiano se organiza en torno a la celebración de los diversos momentos de la vida, pasión, muerte y resurrección de Jesucristo. Hemos de aclarar, por cuanto será un término que aparecerá con frecuencia, que cuando hacemos alusión

36. XVIII-37.

37. Arboleda Goldaracena 2009.

38. Para conocer la evolución de este sacramento hasta los comienzos de la Edad Moderna, puede consultarse: Pérez González 2005a, pp. 54-65.

39. Al tema de la presencia de la mujer, y por ende de los núcleos familiares, en las cofradías ha dedicado varios trabajos la Dra. Ángela Muñoz Fernández: Muñoz Fernández 1990, 1991. El ámbito espacial del estudio no corresponde a la ciudad de Sevilla, pero creemos que las conclusiones de la Dra. Muñoz Fernández son extrapolables al espectro espacio-temporal de nuestro trabajo. Un estudio más reciente, centrado en el ámbito andaluz, es el de la Dra. Silvia María Pérez González: Pérez González 2012.

40. III-37.

41. V-30.

42. II-12; IV-46; IX-49; XVI-33. Véase: Sánchez Herrero 1997.

43. Salas 1990, p. 254.

44. Sánchez Herrero 1989, pp. 296-297.

45. Salas 1990, p. 254. 
a la fiesta de tal o cual solemnidad, la conmemoración se celebraba generalmente con una misa solemne, normalmente cantada, y a veces con vísperas el día anterior. Es un aspecto que no suele especificarse claramente en la mayoría de las reglas, por lo que deducimos que se trataba de un término de sobra conocido por los cofrades.

El año litúrgico comienza oficialmente con el Adviento, el tiempo de preparación para la Navidad. La única referencia que tenemos de este período litúrgico corresponde a la celebración de los cabildos generales de algunas cofradías, el primer $^{46}$ o el cuarto domingo de Adviento ${ }^{47}$.

La Navidad o Natividad de Jesucristo se festeja de forma muy especial por parte de los cofrades. Es una de las tres Pascuas del año ${ }^{48}$, y algunas cofradías celebran en esta fecha su fiesta principal ${ }^{49}$, su cabildo general ${ }^{50}$ o mantienen la costumbre de felicitar a los señores de título eclesiástico o seglar ${ }^{51}$.

Tras la Navidad, llega la fiesta de Año Nuevo ${ }^{52}$, momento de celebración de cabildos generales en algunas corporaciones, aprovechando esta fiesta ${ }^{53} \mathrm{u}$ ocho días después ${ }^{54}$. Este día se conmemora también la fiesta de la Circuncisión de Jesús ${ }^{55} \mathrm{y}$ la del Dulce Nombre de Jesús ${ }^{56}$.

El 6 de enero se celebra la fiesta de la Epifanía o Apparitio Domini, día en el que algunas cofradías celebran su fiesta y cabildo general ${ }^{57}$ y los cofrades pueden ganar diversas indulgencias ${ }^{58}$. Estas fiestas ${ }^{59}$ y la participación de las indulgencias ${ }^{60}$ podían trasladarse al domingo dentro de la octava de la festividad.

El 25 de marzo tiene lugar la fiesta de la Anunciación, con una doble vertiente $^{61}$ : festividad mariana y conmemoración de la Encarnación de Jesucristo ${ }^{62}$.

El segundo tiempo fuerte del año cristiano es la Cuaresma, que sirve como preparación para la Semana Santa. Es un tiempo de recogimiento, oración y penitencia, en el que destaca la práctica de determinadas virtudes como modo de conversión personal. Entre estas prácticas, recogemos la obligación de pedirse perdón entre los cofrades, en un cabildo que determinadas cofradías organizaban

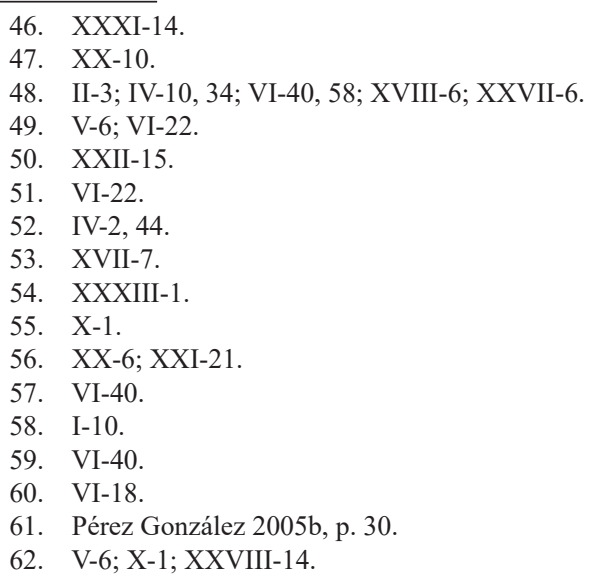


para tal fin ${ }^{63}$. Otras prácticas frecuentes eran la costumbre de oír sermones ${ }^{64} \mathrm{o}$ la petición de limosna para sustentar las obras de caridad ${ }^{65}$, teniendo el limosnero la obligación de dar cuenta de todo lo recaudado en los cabildos correspondientes que habrían de celebrarse cada domingo de Cuaresma en algunas cofradías. Los cuarenta días previos a la Semana Santa eran también un tiempo de celebración de diversos cabildos, sobre todo para la preparación de la salida penitencial ${ }^{66}$. A veces el cabildo, si tenía lugar en domingo, incluía también celebración de misa y algunas cofradías especificaban que los órganos de gobierno de la corporación podían fijar estas reuniones cualquier día del tiempo de Cuaresma ${ }^{67}$.

Tras la Cuaresma, llega la Semana Santa, la gran celebración por antonomasia en el seno de las cofradías, sobre todo las que presentaban una faceta penitencial claramente marcada ${ }^{68}$. Comienza el Domingo de Ramos, día en el que la mayoría de las cofradías que realizarán estación de penitencia durante la semana celebran un cabildo, generalmente para tratar temas relacionados con la salida penitencial ${ }^{69}$.

La estación de penitencia por las calles de Sevilla podía tener lugar desde el Miércoles al Viernes Santo. Este punto ha sido estudiado suficientemente por el Dr. Sánchez Herrero ${ }^{70}$ utilizando la misma documentación que nosotros, por lo que remitimos a la obra citada. Simplemente señalaremos aquí algunos aspectos que consideramos fundamentales para la comprensión de la realidad vivida en esta época, por cuanto en numerosas ocasiones este fenómeno de la penitencia pública en los orígenes de las cofradías ha sido objeto de muchas confusiones y elucubraciones: las cofradías no salen a la calle para realizar estación de penitencia sino hasta bien entrado el siglo XVI, algo que ya hemos aclarado en la introducción a este trabajo. El desfile era por lo general bastante sencillo: cofrades de luz con candelas, cofrades de sangre disciplinándose y algunas imágenes de Jesús o la Virgen vestida de luto portadas con total sencillez, sin flores ni música. Esta era la realidad durante la práctica totalidad del siglo XVI. La gran transformación de la Semana Santa tendrá lugar con el Barroco.

Para probar lo que argumentamos solamente hace falta acudir a la última regla de las que componen nuestro corpus, por ser la más tardía: la de la Hermandad y Cofradía de Nuestra Señora de Regla y Potencia de Cristo, fechada en 1601. Las

63. IV-52.

64. XXXI-10.

65. IV-13; VII-23; IX-20.

66. X-29.

67. XXXII-20.

68. Son las siguientes: Vera Cruz (V), Quinta Angustia (VII), Trinidad (IX), Negritos (XII), Jesús Nazareno (XV), Santa Verónica (XVI), Sagrada Expiración (XXIII), Sangre de Jesucristo (XXV), Buen Fin (XXVII), Sagrados Clavos (XXX), Nuestra Señora de Regla (XXXVI), Traspaso y Soledad (XXXVI) y Gran Poder (XXXIX). Otras corporaciones no necesariamente penitenciales incorporaban este tipo de prácticas durante la Semana Santa: Pura y Limpia Concepción (X), Nuestra Señora de la O (XVIII), Dulce Nombre de Jesús (XXI), Nuestra Señora de la Esperanza (XXXI), Nuestra Señora del Buen Viaje (XXII).Véase: Sánchez Herrero 2003, p. 85.

69. V-13, 39, 45; VII-12, 47; X-2, 24; IX-9; XII-21; XV-32; XVIII-6; XXIII-8, 9, 10; XXIV-9; XXIX-12; XXX-5 XXXIV-9, 17.

70. Sánchez Herrero 2003, pp. 107-110. 
disposiciones recogidas en ellas con respecto a la estación de penitencia ${ }^{71}$ describen una ceremonia bastante simple y acorde aún con la mentalidad pretridentina: se celebra un cabildo preparatorio el Domingo de Ramos, previo a la salida penitencial que tiene lugar el Jueves Santo a partir de las dos de la tarde. Los hermanos han de ir ataviados con una túnica de angeo o presilla, capirote redondo y una cinta negra de cuero que ciñe un escapulario con los símbolos de la cofradía, descalzos o con alpargatas si están enfermos. En el cortejo no se portan imágenes, sino tres estandartes: el del Santísimo Sacramento, el de las Potencias de Cristo y el de la Virgen de Regla.

Los días grandes de la Semana Santa eran el Jueves y el Viernes Santo, días en que también podían celebrarse cabildos de preparación de la estación de peniten$\mathrm{cia}^{72}$. El Jueves Santo tiene un marcado carácter eucarístico, pues se conmemora la última cena de Jesús con sus discípulos ${ }^{73}$. Este día las cofradías "encerraban" el Santísimo Sacramento ${ }^{74}$, que no volvía a sacarse del Sagrario hasta el Viernes Santo $^{75}$.

La Semana Santa culmina con la gran celebración cristiana: la Resurrección de Jesús. Se festeja en la gran mayoría de las cofradías ${ }^{76}$, habida cuenta de su importancia como conmemoración central del credo cristiano. La fiesta solemne, a veces con vísperas, se acompañaba en ocasiones de una procesión ${ }^{77}$. Estas celebraciones podían tener lugar ya desde la madrugada del Sábado Santo al Domingo de Resurrección, con una procesión llevando la imagen de Jesús resucitado y de la Virgen "vestida de alegría"78.

Tras la Resurrección comienza el tiempo pascual, el tercero de los momentos fuertes del año cristiano, sobre el que no tenemos referencias más que para conmemorar su final, con la festividad de Pentecostés, Pascua del Espíritu Santo o Cincuesma. Se celebra en cuatro cofradías ${ }^{79}$. Previamente a la festividad de Pentecostés, tiene lugar la de la Ascensión, que no hemos podido documentar en ninguna de las cofradías mencionadas, pero que se celebraba en Sevilla ya desde la Baja Edad Media ${ }^{80}$.

La siguiente fiesta dentro del ciclo litúrgico es el Corpus Christi, sin duda la más importante después de la Resurrección. Ya desde el siglo XV constituía una gran fiesta cristiana celebrada con toda conmemoración y prestigio en la Península Ibérica $^{81}$. Tiene lugar en fecha variable durante el mes de junio y conmemora la

71. XXXIV-9, 10, 11, 12.

72. $\mathrm{XV}-3$.

73. IV-8, 47; XXI-24.

74. X-2; VIII-6; XVI-61; XXIV-4; XXXIII-8.

75. IV-8; XVI-61.

76. IV-34, 37, 45; VI-58; VIII-6; X-2; XVIII-6, 65; XX-8; XXI-7, 22; XXIV, 6; XXV-22; XXVII-5, 7; XXXIII-9.

77. XVIII-65; XXI-22; XXV-20; XXXIII-9.

78. XXV-20.

79. IV-34; VI-40, 41; XIII-19; XVIII-6.

80. Pérez González 2005b, pp. 33-34.

81. Sánchez Herrero 1989, pp. 277-278. Para conocer el caso concreto de su celebración en Sevilla desde la Baja Edad Media, puede consultarse: Romero Abao 1989; Pérez González 2003. 
presencia de Jesús resucitado en la Eucaristía. Las cofradías, ya sean Sacramentales o no, realizan en este día una fiesta solemne ${ }^{82}$, con procesión para llevar el Santísimo Sacramento a los enfermos ${ }^{83}$. Al ser un día especialmente festivo, algunas cofradías lo celebran con "danzas y regocijos" $"$. Después de esta festividad, algunas corporaciones aprovechan para realizar la elección de oficiales ${ }^{85} \mathrm{o}$ para tomar cuentas al mayordomo ${ }^{86}$.

La última fiesta que documentamos es la de la Transfiguración del Señor ${ }^{87}$, celebrada por una única cofradía. Se conmemora el seis de agosto y se extendió por el Occidente cristiano a partir del siglo $\mathrm{XV}^{88}$.

\section{DIVERSAS PRÁCTICAS DE PIEDAD Y DEVOCIÓN}

Queremos ilustrar finalmente nuestro trabajo con un amplio catálogo de prácticas y formas devocionales cristianas empleadas por los cofrades para dirigirse a Dios, la Virgen o los santos. La primera de estas grandes prácticas es la misa o Eucaristía, momento fundamental de celebración comunitaria para los cristianos. Ya hemos indicado que la misa constituía el acto de culto principal en las fiestas de las cofradías ${ }^{89}$, pero no era el único momento en que los integrantes de las corporaciones se reunían para celebrar la Eucaristía: a veces se celebraban también misas del Espíritu Santo al comienzo de los cabildos ${ }^{90}$, para pedir su inspiración. Algunas cofradías celebraban misa diaria ${ }^{91}$, otras los lunes ${ }^{92}$ o con carácter mensual ${ }^{93}$.

Las reglas especifican algunas disposiciones relacionadas con este momento fundamental de culto: los cofrades han de guardar gran atención y devoción ${ }^{94}$, "considerando que tienen a Dios delante de sí". En las misas solemnes se utiliza incienso ${ }^{95}$ y se ha de tener la cera encendida en determinados momentos ${ }^{96}$ : "en Visperas a la oraçión Magnifica y responso y en misa al Euangelio y a la sacras asta alçar la Hostia húltima vez". También se estipula que, en caso de retraso de

82. X-2; XXII-10; XXIV-1; XXXIII-19.

83. VII-8; VIII-Int; IX-Int; 56; XVI-1, 3, 10, 23; XIX-Int, 5, 6; XXIV-Int, 7, 8, 9; XXVIII-9; XXXIII-7, 8, 19.

84. X-2; XXXIII-21.

85. VIII-7.

86. VIII-8.

87. II-7.

88. Pérez González 2005b, pp. 36-37.

89. III-5; IV-35; VII-4; X-1; XIX-10; XXI-21.

90. IV-59; X-7; XI-3; XIII-19; XV-23; XXVII-7; XXXII-2; XXXIII-1.

91. II-2.

92. XIV-13; XVI-71; XVII-16; XXVIII-13.

93. VIII-6, 28; IX-10, 57; XII-28; XIII-2; XVI-16; XIX-1; XX-9; XXXII-30; XXXIII-19, 20.

94. XXXI-10

95. XIII-3.

96. X-14. 
los cofrades, su llegada a la misa no podrá ser posterior al momento de leer el Evangelio, bajo sanción económica ${ }^{97}$.

Entre las diversas intenciones por las que se ofrecen las misas, aparte de la conmemoración de fiestas o en calidad de sufragio por los difuntos ${ }^{98}$, destacamos la lucha contra las herejías ${ }^{99}$ o el apoyo espiritual a los príncipes cristianos ${ }^{100}$.

Algunas cofradías tienen un clérigo o capellán encargado de decir las diversas misas $^{101}$ y en otras se realizan colectas entre los cofrades para la celebración de estos cultos $^{102}$. Si los cofrades no acuden a misa los domingos y fiestas en la cofradía, han de hacerlo en su parroquia más cercana, como mandan las normas de la Iglesia $^{103}$. Los cofrades también tienen la obligación de acudir a la primera misa de cualquier clérigo que perteneciera a la cofradía antes de ordenarse ${ }^{104}$.

La segunda práctica de devoción que destaca por su frecuencia en la documentación son las indulgencias. Entendemos por indulgencia "la remisión, ante Dios, de la pena temporal debida por los pecados que ya han sido perdonados en cuanto a la culpa, remisión que la autoridad eclesiástica, tomándola del Tesoro de la Iglesia, concede a los vivos a manera de absolución y a los difuntos a manera de sufragio" 105 . Su práctica vivió un auge más que notable durante los siglos medievales, siendo el uso abusivo de las indulgencias uno de los motivos que llevaron a Martín Lutero a escribir sus famosas tesis a comienzos del siglo XVI, encendiendo la mecha para la Reforma Protestante ${ }^{106}$. Igualmente, a finales del siglo XV los Reyes Católicos hubieron de estipular una serie de disposiciones para frenar el abuso en la práctica de las indulgencias en sus reinos ${ }^{107}$.

Así las cosas, ¿qué encontramos en la documentación estudiada con respecto al uso y la práctica de las indulgencias? Las menciones, como decimos, son abundantes, encontrando diversas posibilidades. Los cristianos, especialmente los cofrades, podían ganar indulgencias visitando determinados lugares, como la capilla de algunas cofradías ${ }^{108}$. En diversos momentos del año, como el primero de noviembre y el primero de junio ${ }^{109}$, los sábados ${ }^{110}$, el día de la Epifanía ${ }^{111}$, el domingo dentro de la octava de esta fiesta ${ }^{112}$, o en determinadas conmemoraciones, sobre todo relativas a los santos, lo que demuestra la gran devoción que se les

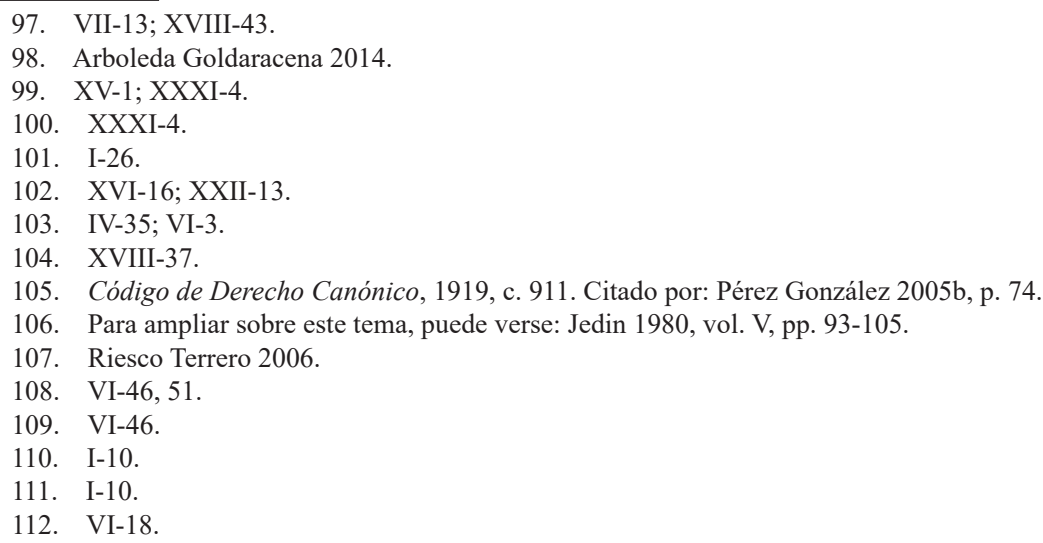


profesaba: san Antón ${ }^{113}$, san Blas, san Francisco, san Juan Bautista, san Miguel Arcángel, santa Catalina, santa Cecilia, santa Margarita, santa María Magdalena o santo Domingo.

Las indulgencias también podían ganarse mediante determinadas actitudes vitales propias del cristiano, como corregir al que jura ${ }^{114}$, pagar la pena por haber jurado ${ }^{115} \mathrm{o}$ asistir a los entierros de los cofrades ${ }^{116}$. En ocasiones, los días de indulgencias en la capilla de la cofradía, se organizaba una justa literaria ${ }^{117}$.

Pasando al devocionario, las oraciones básicas del cristiano para dirigirse a Dios y a la Virgen María son de sobra conocidas: el Padrenuestro ${ }^{118}$ y el Ave María $^{119}$. Las menciones en las reglas tanto para la primera ${ }^{120}$ como para la segunda $^{121}$ son abundantísimas, destacando el número de veces que ha de rezarse y las ocasiones en que ha de hacerse: peticiones varias, celebración de cabildos, sufragios por los difuntos, estación de penitencia, etc.

El credo cristiano quedó definido ya en el siglo IV, asumiendo pocas modificaciones para la rama católica desde esa época ${ }^{122}$. Sin embargo, no hemos encontrado referencias a la recitación de esta oración en la documentación acotada. Sí hemos hallado, no obstante, alusiones al credo como conjunto de creencias cristianas, desarrolladas en un plano teórico al comienzo de una de las reglas ${ }^{123}$.

La oración del Gloria la documentamos una sola vez: los cofrades han de rezarla para gozar de los privilegios de la orden trinitaria ${ }^{124}$.

Dos oraciones marianas importantes son la Salve ${ }^{125}$ y el rosario ${ }^{126}$. Sobre la primera hemos documentado solamente un caso, en la Cofradía de Nuestra Señora de la Esperanza, en que se recomendaba su rezo previamente al ejercicio de la penitencia ${ }^{127}$. Sobre el segundo también documentamos únicamente un caso: en la

113. I-10. Se trata de la misma referencia para todos los santos que nombramos a continuación.

114. XX-4; XXI-1.

115. XXI-1.

116. XX-16.

117. VI-47.

118. Sabugal 1985

119. Morreale 2002. Ambas oraciones, junto con la Salve, aparecen como las tres principales en los compendios de doctrina cristiana de la primera mitad del siglo XVI, algo que refleja la realidad de ese siglo pero también las influencias previas. Véase: Resines 2002.

120. II-8; III-13, 32; IV-Int, 19; V-18; VI-3, 39, 59, 60, 62; VII-17; VIII-28; IX-Int, 14; X-3, 21; XI-Int; XIII-4; XIV-43; XV-16, 17, 23; XVI-Int, 55; XVII-Int, 9, 14, 22; XVIII-27, 59; XIX-10, 12; XXI-38; XXII-12, 31; XXIII-25; XXIV-30; XXVI-14, 42; XXVIII-12; XXXI-13; XXXIII-20, 41.

121. II-8; III-32; IV-Int, 19; V-18; VI-2, 3, 39, 59, 60; VII-17; VIII-28, 29; IX-Int, 14; X-3, 21, 24; XIII-4; XIV-43; XV-17, 23; XVI-Int, 16, 55; XVII-Int, 9, 14, 22; XVIII-27, 59; XIX-12; XXI-38; XXII-12, 31; XXIII-25; XXIV-30; XXVI-14, 42; XXVIII-12; XXIX-10; XXXI-5, 13; XXXIII-20, 41. Se documenta en la gran mayoría de las corporaciones, sean marianas o no.

122. Para el conocimiento de su formación y las controversias en torno al mismo, puede verse la obra: Kelly 1980.

123. III-1.

124. IX-Int.

125. Trinidad 2009; Mundó 1967; Morreale 2004.

126. Labarga García 2003; Para su culto y devoción en Sevilla, puede verse: Romero Mensaque 1990, 2004.

127. XXXI-5. 
introducción de una de las reglas, la de la Santísima Trinidad, los frailes trinitarios del convento donde se hospedaba la cofradía recomendaban a los cofrades que se unieran a ellos en el rezo de comunidad para recitar esta oración ${ }^{128}$.

Los salmos penitenciales se recitaban durante la Semana Santa, como los que documentamos en una de las cofradías ${ }^{129}$ : el salmo Miserere Mei ${ }^{130}$, el De profundis ${ }^{131}$ o la oración Respice quaesumus domine. De los salmos y oraciones propias de los actos fúnebres nos hemos ocupado en otros trabajos ${ }^{132}$.

Otra de las prácticas de devoción era el uso de escapularios. Documentamos varios: el de la orden de los trinitarios ${ }^{133}$, de Santo Domingo con la corona de espinas y las llagas de Jesucristo ${ }^{134}$, de la Sangre de Jesucristo correspondiente al escudo de su cofradía ${ }^{135}$. El uso del escapulario se extendió durante los siglos medievales a raíz de la difusión de la advocación de Nuestra Señora del Carmen ${ }^{136}$. Sin embargo, no hemos documentado referencias a escapularios del Carmen en la documentación.

También destacamos dentro de los actos devocionales la celebración de romerías, que hemos documentado en dos de las cofradías. En el primer caso, se trata de la disposición recogida en una de las reglas, la de la Cofradía de San Pedro, de celebrar honras fúnebres por el cofrade que fallezca lejos de la ciudad, sea cual sea el motivo de su ausencia, entre los que se recogen el de ir de romería ${ }^{137}$. Por otra parte, una de las cofradías estudiadas estaba constituida bajo la advocación de Nuestra Señora de Cuatrovitas, que se venera en su ermita de Bollullos de la Mitación, por lo que los cofrades habían de ir cada año el día de su fiesta (15 de agosto) a conmemorar su solemnidad en dicha ermita. No se especifica expresamente que se trate de una romería, pero entendemos que la tipología de la fiesta corresponde a una celebración similar:

"Otrosí, hordenamos y tenemos por bien que fagamos en cada un año la fiesta de Nuestra Señora de Quatravita para siempre jamás en su propio día de Quatroavita, que es el día de Nuestra Señora de Agosto, la qual fiesta abemos de yr a celebrar en su misma casa y ermita, se a de facer con toda la solem- //6r nidad que se pudiere, disciendo sus Visperas cantadas y otro día su missa cantada con ministros y sermón y proseción muy solemne. A la qual dicha fiesta abemos de yr todos los cofrades sin faltar ninguno, si no fuere por enfermedad, de estar en prición o muy lejos desta ciudad, so pena de dos libras de cera al cofrade que no fuere a la dicha Cofradia" $" 138$.

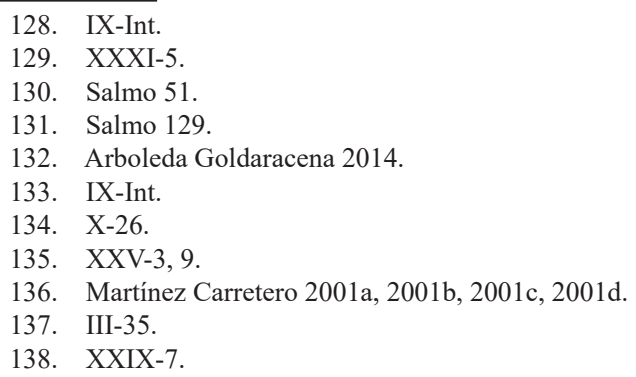


Por último, no podemos pasar por alto la celebración de procesiones. Ya hemos hecho alusión a las procesiones penitenciales, las del Corpus Christi o las de la imagen de Jesús resucitado el día de Pascua florida. Pero hemos documentado otras. Las procesiones podían tener lugar con motivo de fiestas marianas: Nuestra Señora de Agosto ${ }^{139}$, Nuestra Señora de $\mathrm{Marzo}^{140}$, Nuestra Señora de Septiembre $^{141}$, Nuestra Señora de Cuatrovitas ${ }^{142}$ o Nuestra Señora de la Granada ${ }^{143}$, estas dos últimas festejadas el 15 de agosto.

Igualmente se organizaban procesiones para conmemorar fiestas cristológicas, como el Dulce Nombre de Jesús ${ }^{144}$ o la Santa Cruz ${ }^{145}$, o de los santos: Santas Justa y Rufina ${ }^{146}$ o Santiago ${ }^{147}$. También se celebraban en sufragio por los difuntos ${ }^{148}$ y algunas veces los participantes ganaban indulgencias ${ }^{149}$. Hemos documentado igualmente la celebración de procesiones de rogativas: en caso de pestilencia, hambre, sequía, guerra o enfermedad del rey ${ }^{150}$.

En cuanto al orden en que debía formarse el cortejo, en una de las reglas hemos hallado la siguiente disposición, bastante ilustrativa de la realidad que podía encontrarse en la época estudiada, y con la que cerramos el presente apartado:

"Item, constituymos y ordenamos que en las nuestras proçessiones y entierros se tenga y guarde este conçierto y orden. Que los nuestros alcaldes cada vno tome su vara de regimiento y hagan poner en dos coros todos los cofrades con su çera. $Y$ los primeros sean diputados con sus hachas y luego los cofrades más ançianos. Y por esta horden vayan en su prosseçión"151.

\section{CONCLUSIONeS}

Creemos que, por todo lo argumentado, ha quedado bastante ilustrada la sucesión de ciclos, momentos y prácticas mediante las cuales los cofrades sevillanos de la Baja Edad Media y los comienzos de la modernidad organizaban sus vidas en torno a las creencias cristianas que profesaban. Podemos, no obstante, realizar algunas precisiones finales al respecto.

Las menciones a los distintos sacramentos de la Iglesia católica en la documentación estudiada no son tan abundantes como cabría esperar. Esto se debe a las ca-

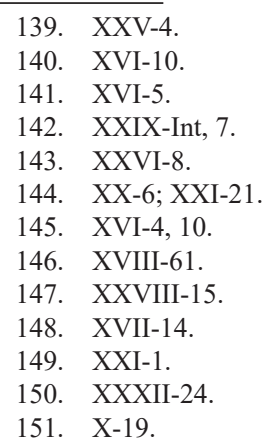


racterísticas de los documentos en sí: las reglas de las cofradías no son la categoría diplomática más directamente relacionada con este tipo de cuestiones, sobre las que se legislaba en los distintos sínodos y $\operatorname{concilios}^{152}$ y cuya práctica se reflejaba en los documentos generados por las parroquias ${ }^{153}$, lugar preferente para su administración. Las cofradías, aunque se integren en ellas, no eran ni son parroquias $\mathrm{y}$, por tanto, no les corresponde directamente la administración sacramental. No obstante, podemos constatar que la mayoría de los sacramentos se conocían y se practicaban: hemos documentado referencias a seis de los siete sacramentos católicos, dejando a un lado la confirmación, cuya práctica no era muy habitual, como ya hemos apuntado. Entre los más frecuentes podemos destacar tres: en primer lugar, el bautismo, que no se menciona directamente en demasiados casos, pero que constituye un elemento clave al ser la puerta de acceso al seno de la Iglesia y, por tanto, a la pertenencia a las distintas cofradías. Por otra parte, los sacramentos de la confesión y la comunión, que generalmente van unidos, constituyen los otros dos elementos que configuran la tríada de sacramentos fundamentales. Su práctica está relacionada con el seguimiento de unas pautas de vida atendiendo a las enseñanzas evangélicas, de manera que la frecuencia de estos sacramentos ayuda a los cristianos a mantenerse más cerca de Dios y actuar en sus vidas diarias de acuerdo a sus mandatos. Esto justifica su supremacía absoluta sobre otros sacramentos. Por último, destacaremos el matrimonio, puesto que constituía sin duda una puerta abierta a la participación de núcleos familiares completos en el seno de las cofradías, gozando todos ellos de los beneficios debidos.

Hemos comprobado que el año litúrgico marcado por la tradición de la Iglesia católica se observaba y practicaba en el seno de las cofradías, con referencias documentadas para todos los tiempos fuertes del año (Adviento, Cuaresma y Pascua) y las fiestas celebradas en cada momento del ciclo anual. Podemos afirmar que el tiempo con mayor presencia de menciones, y por tanto de celebraciones, es el relacionado directamente con la pasión y muerte de Jesús, abarcando su preparación mediante la Cuaresma y su culmen con la fiesta de la Resurrección, la conmemoración central para los cristianos. La mayor concentración de actos y cultos en estas fechas se explica por un doble motivo: en primer lugar, por tratarse de los momentos culminantes del año cristiano, no solamente para los cofrades sevillanos, sino para los fieles de todo el orbe. Y en segundo, por el carácter penitencial de la mayoría de corporaciones recogidas en nuestro corpus documental, algo que las llevará a organizar su vida interna y su proyección social en torno a la celebración de la Semana Santa y la Resurrección de Jesús. La práctica de la penitencia pública era igualmente un momento clave para las corporaciones con esta faceta, un elemento que ha contribuido sin duda a la evolución posterior de las corpora-

152. Para conocer la documentación relativa a todos los sínodos y concilios provinciales celebrados en Sevilla desde el año 590 al 1604: Sánchez Herrero 2008.

Para conocer el alcance de este tipo de documentación para estudiar los fenómenos ligados a la religiosidad popular, puede verse: Marcos Martín 1989.

153. Un amplio catálogo de toda la documentación conservada en los archivos parroquiales de Sevilla puede consultarse en: Morales Padrón 1981. 
ciones, hasta llegar al fenómeno que conocemos hoy en día. Otra de las fiestas importantes y muy conmemorada por las cofradías era el Corpus Christi, devoción muy extendida en Sevilla ya desde el siglo XV, celebrándose procesiones por parte de un buen número de cofradías para llevar el Santísimo a los enfermos, o participando en la gran procesión que se organizaba desde la Catedral.

Por último, hemos podido recorrer las diversas prácticas de piedad que los cofrades llevaban a cabo para manifestar su filiación a Dios, la Virgen o los santos. Las misas, en primer lugar, constituían el acto de culto fundamental, celebrándose en multitud de ocasiones y con una gran variedad de fines. En un segundo puesto ubicamos la práctica de las indulgencias, tan extendida durante los siglos bajomedievales y la primera centuria moderna que constituyeron uno de los motivos desencadenantes de la Reforma protestante. Nosotros hemos podido certificar que su uso estaba también muy extendido en la Sevilla de los siglos XIV a XVI. Por otra parte, constatamos que las oraciones con más presencia en la documentación, por lo que podemos deducir que probablemente fueran las más practicadas, son el Padrenuestro y el Ave María, piezas clave dentro del devocionario católico y muestra del arraigo en la mentalidad colectiva de las dos figuras centrales del cristianismo: Dios, en primer lugar, y la Virgen María, en segundo. Otra de las prácticas más frecuentes eran las procesiones, tan ligadas a la concepción histórica y actual de las cofradías sevillanas. Las procesiones constituyen el principal acto de culto externo para estas corporaciones, sirviendo en muchos casos como un verdadero ejercicio de pública protestación de fe de cara al resto de la ciudad. No obstante, se trataba de cortejos bastante sencillos, portando imágenes sagradas en algunos casos, pero, al igual que sucedía con los desfiles penitenciales, imperaba la sencillez.

Podemos concluir que los cofrades sevillanos de la época estudiada conocían y llevaban a cabo con total normalidad las diversas prácticas devocionales propias del cristianismo católico, siguiendo el magisterio de la Iglesia en cuanto a la conmemoración de los momentos centrales del año litúrgico y a la celebración de los sacramentos, ocasiones privilegiadas de unión con Dios y de manifestación de pertenencia a la comunidad.

\section{BIBLIOGRAFÍA}

Arboleda Goldaracena, Juan Carlos (2009), "La labor de los clérigos en el seno de las cofradías de la Vera-Cruz andaluzas (s. XVI)", Actas del IV Congreso Internacional de Hermandades y Cofradias de la Vera-Cruz, Zamora, pp.799-808.

Arboleda Goldaracena, Juan Carlos (2013), "La caridad en la historia del cristianismo: algunas manifestaciones en la Andalucía bajomedieval", Medievalista, $\mathrm{n}^{\mathrm{o}}$ 14, disponible en: http://www2.fcsh.unl.pt/iem/medievalista/MEDIEVALISTA14/goldaracena1403.html

Arboleda Goldaracena, Juan Carlos (2014), "Los laicos y su actitud ante la muerte en la Sevilla de la Baja Edad Media y los comienzos de la modernidad", Miura Andrades, José María (Dir.); Arboleda Goldaracena, Juan Carlos (Coord.), 
Lágrimas en la lluvia. Estudios sobre la muerte y los muertos, Sevilla, pp. 291-300.

Arboleda Goldaracena, Juan Carlos (2015), "La práctica de la doctrina cristiana en las cofradías de Sevilla durante la Baja Edad Media y los comienzos de la modernidad", Roda Peña, José (Dir.), XVI Simposio sobre Hermandades de Sevilla y su provincia, Sevilla, pp. 15-40.

Cañizares Japón, Ramón (2014), Las antiguas Reglas de la Hermandad de la Soledad de Sevilla, Sevilla.

Fernández Conde, Francisco Javier (2011), La religiosidad medieval en España. Baja Edad Media (siglos XIV y XV), Oviedo.

García Cárcel, Ricardo; Palau I Orta, Josep (2006), "Reforma y Contrarreforma católicas", Cortés Peña, Antonio Luis (Coord.), Historia del cristianismo. III. El mundo moderno, Granada, pp. 187-226.

Jedin, Hubert (1980), Manual de Historia de la Iglesia. Barcelona, 10 vols.

Kelly, J.N.D (1980), Primitivos Credos cristianos, Salamanca.

Labarga García, Fermín (2003), "Historia del culto y devoción en torno al Santo Rosario”, Scripta Theologica, 35-1, pp. 153-176.

Lozano Ruiz, Carlos; Torremocha, Margarita (2013), “Asistencia social y cofradías en el Antiguo Régimen. Historiografía, líneas de investigación y perspectivas", Chronica Nova, 39, pp. 19-46.

Maldonado, Luis (1989), "La religiosidad popular", Álvarez Santaló, Carlos et al., La religiosidad popular, Barcelona, vol. I, pp. 30-43.

Mandianes Castro, Manuel (1989), "Caracterización de la religión popular", Álvarez Santaló, Carlos et al., La religiosidad... ob.cit., vol. I, pp. 44-54.

Mantecón, Tomás (1990), Contrarreforma y religiosidad popular en Cantabria. Las cofradias religiosas, Santander.

Marcos Martín, Alberto (1989), "Religión predicada y religión vivida. Constituciones sinodales y visitas pastorales: ¿un elemento de contraste?”, Álvarez Santaló, Carlos et al., La religiosidad... ob.cit., vol. II, pp. 46-56.

Martín-Viveros Tajuelo, Antonio (2012), "Las cofradías castellanas en la Edad Media. Pasado, presente y futuro de la producción historiográfica", Espacio, Tiempo y Forma. Serie III. Historia Medieval, t. 25, pp. 285-308.

Martínez Carretero, Ismael (2001a-b-c-d), "El Escapulario del Carmen, entre la tradición y la historia" (4 partes), Boletín de las cofradias de Sevilla, 510 (pp. 24-25), 511 (pp. 24-25), 512 (pp. 28-29), 513 (pp. 29-31).

Mira Caballos, Esteban (2004), Pontificia y Real Hermandad y Cofradía de Nazarenos de Nuestro Padre Jesús del Gran Poder y María Santísima del Mayor Dolor y Traspaso. Sus reglas de 1570. Transcripción y estudio, Sevilla.

Mitre Fernández, Emilio (2004), "Entre el nacimiento a la vida y el más allá: vías de perfección y salvación", Mitre Fernández, Emilio (coord.), Historia del cristianismo. II. El mundo medieval, Granada, pp. 303-311.

Morales Padrón, Francisco (1981), Los archivos parroquiales de Sevilla, Sevilla.

Morreale, Margherita (2002), "El Ave María en la enseñanza de la doctrina cristiana entre 1496 y 1596”, Saralegui Platero, Carmen; Casado Velarde, Manuel, 
Pulchre, bene, recte. Homenaje al Prof. Fernando González Ollé, Pamplona, pp. 971-980.

Morreale, Margherita (2004), "La Salve Regina en las Doctrinas cristianas y cartillas del s. XVI”, Revista de filología española, 84-1, pp. 129-151.

Mundó, Anscari M (1967), "El origen de la Salve visto desde España”, Anuario de Estudios Medievales, 4, pp. 369-376.

Muñoz Fernández, Ángela (1990), "Parentesco artificial / parentesco natural en la vertebración social de las cofradías devocionales. Dos ejemplos madrileños de los siglos XV y XVI", CEIRA, 1, pp. 369-391.

Muñoz Fernández, Ángela (1991), "Las mujeres en los ámbitos institucionales de la religiosidad laica: las cofradías devocionales castellanas”, Muñoz Fernández, Ángela; Graña Cid, María del Mar, Religiosidad femenina: expectativas y realidades (ss. VIII-XVIII), Madrid, pp. 93-114.

Pérez González, Silvia María (2003), "La presencia de las cofradías en la fiesta del Corpus Christi en Sevilla a finales del siglo XV y comienzos del XVI", Boletín de las Cofradias de Sevilla, 532, pp. 450-451.

Pérez González, Silvia María (2005a), La mujer en la Sevilla de finales de la Edad Media: solteras, casadas y vírgenes consagradas, Sevilla.

Pérez González, Silvia María (2005b), Los laicos en la Sevilla bajomedieval: sus devociones y cofradias, Huelva.

Pérez González, Silvia María (2012), "Mujeres y cofradías en la Andalucía de finales de la Edad Media", Historia. Instituciones. Documentos, 39, pp. 185-211.

Resines, Luis (2002), "La Summa de la Doctrina Cristiana de Alonso Martínez de Laguna”, Berceo, 142, pp. 93-132.

Riesco Terrero, Ángel (2006), "Real Provisión de los Reyes Católicos (Medina del Campo, 22-VI-1497) relativa al control de abusos introducidos en los principales reinos de España con motivo de la predicación y publicación de las indulgencias pontificias y de la cuestación y recaudación de limosnas y donativos ofrecidos para lucrar tales gracias", Documenta \& Instrumenta, 4, pp. 61-80.

Romero Abao, Antonio (1989), "La fiesta del Corpus Christi en Sevilla en el siglo XV”, Álvarez Santaló, Carlos et al., La religiosidad... ob.cit., vol. III, pp. 19-29.

Romero Mensaque, Carlos José (1990), Estudio histórico de las hermandades de gloria de Nuestra Señora del Rosario de la ciudad de Sevilla y descripción artística de su patrimonio, Sevilla.

Romero Mensaque, Carlos José (2004), El rosario en Sevilla: devoción, rosarios públicos y hermandades (siglos XVI-XXI), Sevilla.

Sabugal, Santos (1985), "Hacia el origen histórico del Padrenuestro", Religión y cultura, vol. 31, 144, pp. 41-56.

Salas Delgado, Luis (1990), "Formación cristiana y práctica sacramental en la feligresía de San Andrés en la Sevilla de los siglos XV y XVI", CEIRA, 1, ob. cit., pp. 250-254.

Sánchez Herrero, José (1985), “Las cofradías sevillanas. Los comienzos”, Sánchez Herrero, José et al. (Eds.), Las cofradias de Sevilla: historia, antropología, arte, Sevilla, pp. 9-34. 
Sánchez Herrero, José (1988), "Las cofradías de Semana Santa de Sevilla durante la modernidad. Siglos XV a XVII”, Sánchez Mantero, Rafael et al. (Eds.), Las cofradías de Sevilla en la modernidad, Sevilla, pp. 27-88.

Sánchez Herrero, José (1989), “Algunos elementos de la religiosidad cristiana popular andaluza durante la Edad Media”, Álvarez Santaló, Carlos et al., La religiosidad..., ob.cit., vol.1, pp. 268-307.

Sánchez Herrero, José (1995), "El origen de las cofradías penitenciales", VV.AA. (Eds.), Sevilla Penitente, Sevilla, vol. I, pp. 13-55.

Sánchez Herrero, José (1996), "El origen de las cofradías de Semana Santa o de Pasión en la Península Ibérica", Temas Medievales, 6, pp. 31-79.

Sánchez Herrero, José (1997), "La acción benéfica de las cofradías durante los siglos XIV al XVII: la redención de cautivos y la dotación de doncellas para el matrimonio", Campos y Fernández De Sevilla, Francisco Javier, Religiosidad Popular en España. Actas del Simposium (I), San Lorenzo del Escorial, pp. 163-191.

Sánchez Herrero, José (1999), "Piedad y artes plásticas. La devoción a la Preciosa Sangre de Cristo durante los siglos XIII a los primeros años del XVI y su influencia en las manifestaciones artísticas", Actas do Colóquio Internacional: Piedade popular. Sociabilidades-Representaçoes-Espiritualidades, Lisboa, pp. 411-432.

Sánchez Herrero, José (2003), La Semana Santa de Sevilla, Madrid.

Sánchez Herrero, José (2004), "Desde el cristianismo sabio a la religiosidad popular en la Edad Media", Clio \& Crimen, 1, pp. 301-335.

Sánchez Herrero, José (2008), Synodicon Baeticum. Constituciones conciliares y sinodales del Arzobispado de Sevilla: años 590 al 1604, Sevilla.

Sánchez Herrero, José (en línea), "La evolución de las hermandades y cofradías desde sus momentos fundacionales hasta nuestros días", Consejo General de Hermandades y Cofradias de la Ciudad de Sevilla, disponible en: http://www. hermandades-de-sevilla.org/hermandades/historia-de-las-hermandades-y-cofradia/introduccion [Última consulta: 8 de septiembre de 2015]

Sánchez Herrero, José; Pérez González, Silvia María (1996), "El Sínodo de Sevilla de 1490", Archivo Hispalense, 241, pp. 69-96.

Sánchez Herrero, José; Pérez González, Silvia María (1999), "La Cofradía de la Preciosa Sangre de Cristo de Sevilla. La importancia de la devoción a la Preciosa Sangre de Cristo en el desarrollo de la devoción y la imaginería de la Semana Santa", Aragón en la Edad Media. Homenaje a la profesora Carmen Orcástegui Gros, 14-15, pp. 1429-1452.

Sánchez Herrero, José; Pérez González, Silvia María (2002), CXIX Reglas de Hermandades y Cofradías andaluzas. Siglos XIV, XV y XVI, Huelva.

Trinidad, Gemma de la (2009), "El origen de la Salve Regina", Vida sobrenatural. Revista de teología mística, 664, pp. 300-311.

Fecha de recepción del artículo: octubre de 2015

Fecha de aceptación y versión final: marzo de 2016 